\title{
Production rates and metabolism of short-chain fatty acids in the colon and whole body using stable isotopes
}

\author{
Etienne Pouteau ${ }^{1 *}$, Patrick Nguyen ${ }^{2}$, Olivier Ballèvre ${ }^{1}$ and Michel Krempf ${ }^{3}$ \\ ${ }^{1}$ Nestlé Research Center, Nestec Ltd, PO Box 44, Vers-Chez-Les-Blanc, 1000 Lausanne 26, Switzerland \\ ${ }^{2}$ Unité de Nutrition et Alimentation, Ecole Nationale Vétérinaire de Nantes, Nantes, France \\ ${ }^{3}$ Centre de Recherche en Nutrition Humaine, Groupe Métabolisme, Nantes, France
}

\begin{abstract}
Short-chain fatty acids (SCFA; mainly acetate, propionate and butyrate) are largely produced in non-ruminants during the colonic bacterial fermentation of non-digestible carbohydrates. These intestinal exogenous SCFA pass in part through the splanchnic bed and reach the peripheral bloodstream, mixing with the endogenous circulating SCFA. The whole-body turnover of SCFA is thus composed of an endogenous peripheral turnover and an exogenous production that depends on dietary intake of non-digestible carbohydrates. In the present work methods were developed for determining the SCFA turnover in animals and in human subjects using stable isotopes. The original studies performed to determine endogenous and exogenous metabolism of SCFA in animals and in human subjects are summarised. Using intravenous infusion of ${ }^{13} \mathrm{C}$-labelled SCFA the whole-body turnover of acetate, propionate and butyrate was assessed in rats in a fasted state. The endogenous turnover of acetate and its oxidation were determined in healthy human subjects in the post-absorptive state, using intravenous infusion of $\left[1-{ }^{13} \mathrm{C}\right]$ acetate. Intragastric tracer infusions were performed to evaluate the splanchnic first-pass retention of acetate in adults. Finally, an original model was developed in healthy human subjects using intravenous infusion of $\left[1-{ }^{13} \mathrm{C}\right]$ acetate to determine in vivo the true colonic acetate production after ingestion of a nondigestible disaccharide. These present studies using stable isotopes provide the basis for a novel strategy to evaluate in vivo, in human subjects, the production of SCFA in the large intestine.
\end{abstract}

Short-chain fatty acids: Whole-body and colonic production: Stable isotopes

Short-chain fatty acids (SCFA) are largely produced in nonruminants from colonic or caecal bacterial fermentation of non-digestible carbohydrates, with acetate, propionate and butyrate representing $\leq 70,15$ and $15 \%$ respectively (Bergman, 1990). Since SCFA are major participants in gut maintenance and may also be beneficial active contributors to the peripheral metabolism in human subjects (Bergman, 1990; Macfarlane \& Cummings, 1991; McIntyre et al. 1993; Veldman et al. 1999), numerous investigations have been undertaken to develop a method for accurately determining SCFA production.

The production of SCFA has been assessed using in vitro models (Barry et al. 1995) and in vivo in pigs, dogs and rats (Bergman, 1990; Bleiberg et al. 1992; Rémésy et al. 1995) and also in human subjects (Cummings et al. 1986). However, no approach has been satisfactory in determining the true colonic production of SCFA in situ in healthy human subjects. Several authors have determined SCFA production in human faeces (Bergman, 1990), which actually represents the state of the rectum and not that of the caeco-colon. Some authors have measured SCFA concentrations in the peripheral blood circulation where the majority of SCFA had already been catabolised (Pomare et al. 1985; Rumessen et al. 1992). The production rate of SCFA has been inadequately described, especially that of the colon in healthy human subjects. No clear agreement on acetate turnover emerges from the literature. Using radioactive tracers, Skutches et al. (1979) and Seufert et al. (1984) determined the whole-body acetate turnover to be about $6-8 \mu \mathrm{mol} / \mathrm{kg}$ per min in human subjects and $1 \mu \mathrm{mol} / \mathrm{kg}$ per min in an obese patient in the post-absorptive state. Rocchiccioli et al. (1989) and Kien et al. (1992) found an acetate turnover of 54 and $64 \mu \mathrm{mol} / \mathrm{kg}$ per min in an adult and in preterm infants respectively using stable-isotope-labelled tracers. Recently, Mittendorfer et al. (1998) evaluated the acetate turnover to be $3.4 \mu \mathrm{mol} / \mathrm{kg}$ per min in healthy adults in the post-absorptive state using a $\left[1,2-{ }^{13} \mathrm{C}\right]$ acetate tracer. For propionate Sbaï et al. (1994) reported a turnover of 
$0.64 \mu \mathrm{mol} / \mathrm{kg}$ per min in patients with propionic acidaemia using a $\left[1-{ }^{13} \mathrm{C}\right]$ propionate tracer. No data are available for butyrate whole-body turnover in human subjects. The production and utilisation rates of SCFA in the whole body have not been established either in human subjects or in nonruminants. The in vivo colonic SCFA production rate is still inaccessible, with good reason, and needs to be verified in healthy adults.

In the following work major aspects of the turnover of SCFA in the whole body are demonstrated using a stableisotope approach. The objective was to determine precisely in animals and in human subjects those SCFA that originate from the endogenous metabolism and those that originate from the exogenous and colonic supply. The endogenous and exogenous production rates of SCFA constitute the two major components of the whole-body turnover of peripheral SCFA. Endogenous turnover of SCFA in the peripheral circulation was evaluated in rats, dogs and human subjects. From the determination of the endogenous production of SCFA using the isotope-dilution technique, a model was developed in human subjects to evaluate the exogenous flux of SCFA originating from the intestinal fermentation of non-digested carbohydrate. The final study quantified the colonic production of acetate in healthy human adults who had received an oral dose of non-digestible disaccharide.

\section{Principle of the isotope-dilution technique to assess turnover}

The isotope-dilution technique used in the following work was based on a closed volume of distribution of a metabolite (e.g. acetate in the peripheral blood volume) in which the production and elimination rates were at a steady-state. In that volume at equilibrium the labelled tracer (e.g. $\left[1-{ }^{13} \mathrm{C}\right]$ acetate) was infused at a constant and known rate until a new steadystate had been reached. Samples of blood (representative of the volume of distribution) were then collected at regular intervals, and the amount of label (isotopic enrichment) was determined using MS. From the isotopic enrichment at a steady-state the production or elimination rates of the metabolite of interest could be calculated. The level of isotopic enrichment was inversely proportional to the production and elimination rates; the lower the enrichment, the higher the production rate, with high production reducing the isotopic enrichment. The production (rate of appearance) and utilisation (rate of disappearance) rates represent the turnover at steady-state.

\section{Isotopic enrichments and concentrations of short-chain fatty acids in plasma}

Analyses of SCFA concentration in portal-vein plasma (or in faeces) have been performed in a number of laboratories and there have been no major analytical difficulties (Dankert et al. 1981; Cummings et al. 1986; Rémésy et al. 1995). However, simultaneous analysis of SCFA concentrations, and particularly isotopic enrichments, in human arterial or venous plasma are more challenging (Simoneau et al. 1994; Powers et al. 1995, Pouteau et al. 2001), as these measurements, especially that of acetate, are subject to substantial contamination because acetate is a ubiquitous molecule. As a result, particular attention needs to be paid to avoiding (or minimising) contamination in all reagents and in all preparation steps, and to reporting consistent and reproducible measurements. Our procedures for the analysis of plasma SCFA concentrations and isotopic enrichments have been described previously (Simoneau et al. 1994; Pouteau et al. 2001). Briefly, plasma was deproteinised, the supernatant fraction acidified with $\mathrm{HCl}$ and the organic acids isolated using a diethyl ether extraction procedure. The organic acids were then converted to tert-butyl-dimethyl-silyl-SCFA derivatives. The final solution was injected into a GC connected to a quadrupole MS. Chemical ionisation and selected ion monitoring were used to enhance sensitivity. $\left[{ }^{2} \mathrm{H}\right]$ acetate was used as an internal standard for simultaneous measurement of concentrations and isotopic enrichments of $\left[1-{ }^{13} \mathrm{C}\right]$ acetate, $\left[1-{ }^{13} \mathrm{C}\right]$ propionate and $\left[1-{ }^{13} \mathrm{C}\right]$ butyrate. Plasma concentrations were expressed in $\mu \mathrm{mol} / 1$ and isotopic enrichments in mole percent excess (MPE).

\section{Calculation of whole-body turnover}

\section{Rate of appearance of endogenous short-chain fatty acids}

The endogenous rates of appearance ( $\mu \mathrm{mol} / \mathrm{kg}$ per min) of acetate, propionate or butyrate in the whole-body circulation were calculated according to the equation for steady-state during the last hour of kinetic studies on individuals in the fasted or post-absorptive ( $12 \mathrm{~h}$ overnight-fasted) state. From the determination of isotopic enrichment of each SCFA in plasma (MPE) and knowing the infusion rate $(\mu \mathrm{mol} / \mathrm{kg}$ per min), the rate of appearance (whole-body or endogenous turnover; Wolfe, 1992; Pouteau et al. 1996) was calculated. Endogenous turnover was assessed in subjects in the fasted or post-absorptive steady-state with no (or minimal) colonic SCFA production.

The oxidation rate $(\mu \mathrm{mol} / \mathrm{kg}$ per $\mathrm{min})$ of acetate was then calculated from the ${ }^{13} \mathrm{C}$-isotopic enrichments of expired $\mathrm{CO}_{2}$ :plasma acetate according to the calculation of Wolfe (1992), taking into account the $\mathrm{CO}_{2}$ flux variable measured by indirect calorimetry.

\section{Splanchnic first-pass retention}

Splanchnic first-pass retention (intestine and liver first-pass retention) was determined as the difference between the rate of appearance of acetate during intravenous tracer infusion and the apparent rate of appearance during intragastric infusion of $\left[1-{ }^{13} \mathrm{C}\right]$ acetate (Pouteau et al. 1996).

\section{Exogenous and colonic acetate production}

Although volunteers were not in the steady-state after ingestion of a non-digestible carbohydrate, the whole-body acetate turnover $(\mu \mathrm{mol} / \mathrm{kg}$ per $\mathrm{min}$ ) was calculated using the equation for steady-state according to Miles et al. (1987) and Jensen et al. (1990). The equivalence of steady- and non-steady-state equations was tested by intravenously infusing healthy volunteers with labelled acetate and an increasing amount of unlabelled acetate. The instantaneous whole-body acetate turnover was calculated using the steady-state equation at each sampling point during the 


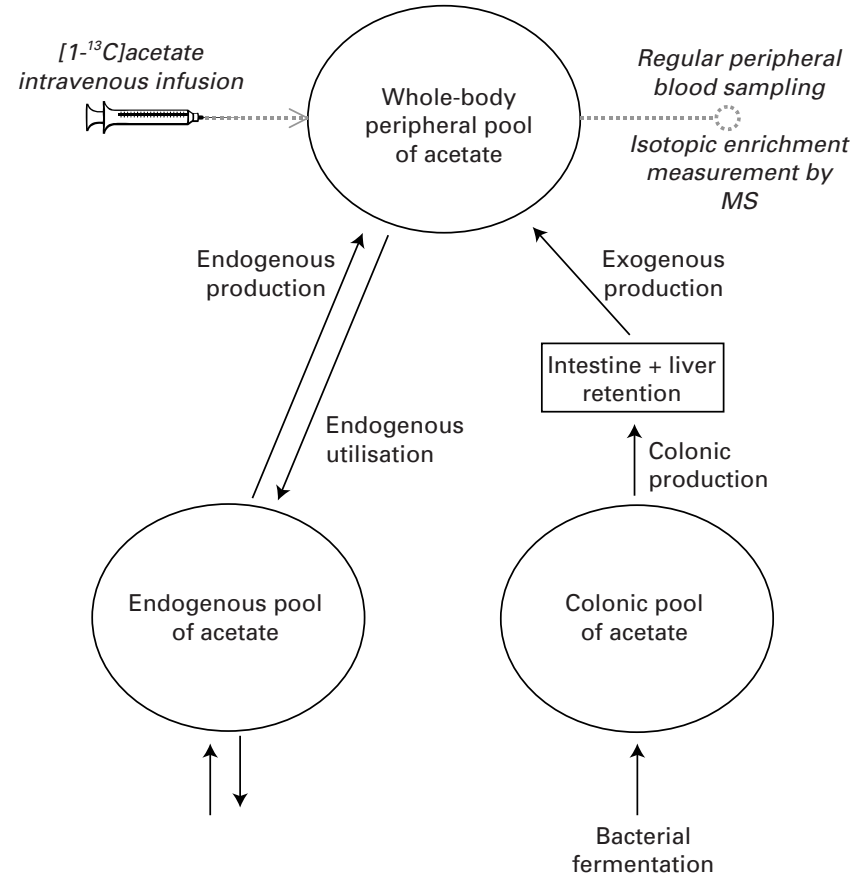

Fig. 1. Model of the whole-body peripheral pool of acetate in healthy adult human subjects. The whole-body peripheral turnover of acetate is determined by the rates of endogenous turnover and the exogenous production. Whole-body turnover is assessed from isotopic enrichment measurements on blood samples following an intravenous continuous infusion of $\left[1-{ }^{13} \mathrm{C}\right]$ acetate tracer in healthy volunteers. Exogenous production is defined as colonic production after accounting for splanchnic retention. The colonic production of acetate following intake of non-digestible carbohydrate is obtained after determination of the endogenous turnover and the splanchnic retention.

kinetic study. This whole-body acetate turnover represented the endogenous turnover and the exogenous production according to our model (Fig. 1).

Exogenous acetate production ( $\mu \mathrm{mol} / \mathrm{kg}$ per min) was obtained following intake of non-digestible carbohydrate, from the difference between whole-body acetate turnover and the endogenous production measured before fibre intake (Pouteau et al. 1998b). Endogenous acetate turnover and instantaneous whole-body turnover were estimated before and after lactulose ingestion respectively. The rate of appearance of exogenous acetate in the peripheral circulation beyond the hepatic filter was calculated, and finally the colonic production was derived (Fig. 1). For development of the model it was confirmed that the endogenous production was unchanged for that range of acetate concentrations $(<550 \mu \mathrm{mol} / \mathrm{l})$ and with a low physiological exogenous supply $(<11 \mu \mathrm{mol} / \mathrm{kg}$ per $\mathrm{min})$. Exogenous acetate production was the quantity of acetate (mol) per unit time measured in the systemic blood circulation that had been recovered from colonic fermentation and the splanchnic retention. The recovery $(\mathrm{mmol})$ during $6 \mathrm{~h}$ observation was measured from the area under the curve of exogenous acetate production, using a trapezoidal method. Colonic acetate production $(\mathrm{mmol})$ was calculated from the exogenous acetate entering the systemic circulation, taking into account the splanchnic first-pass retention of acetate.

\section{In vivo studies of short-chain fatty acid endogenous metabolism}

The endogenous metabolism of SCFA originates from body cells producing and utilising SCFA; cells having the necessary enzymes. This information is available, particularly for acetate. Knowles et al. (1974) have demonstrated the activities of acetyl-CoA hydrolase and synthetase that respectively release acetate into, and take up acetate from, the peripheral circulation. In a comparison with ruminant species Annison \& White (1962) described in sheep an endogenous turnover of acetate additional to the exogenous rumen turnover. In non-ruminant species the endogenous production of SCFA should probably account for a major part of the whole-body peripheral production of SCFA. To evaluate the endogenous metabolism of SCFA, subjects were studied in the post-absorptive or the fasted state. Under such physiological conditions the intestinal fermentation process was minimised, as well as intestinal SCFA production. A series of determinations of whole-body acetate turnover were carried out in healthy human volunteers in the post-absorptive state (Pouteau et al. 1996). A primed constant infusion of $\left[1-{ }^{13} \mathrm{C}\right]$ acetate was administered

Table 1. Endogenous turnover of short-chain fatty acids: turnover (rate of appearance) of acetate, propionate and butyrate determined using the same stable-isotope-labelled tracer approach in rats, dogs and human subjects (from Pouteau et al. 1996, 1998a) and oxidation of acetate and its contribution to resting energy expenditure in human subjects (from Pouteau et al. 1996)* (Values are means with their standard errors)

\begin{tabular}{|c|c|c|c|c|c|c|}
\hline & \multicolumn{2}{|c|}{ Turnover ( $\mu \mathrm{mol} / \mathrm{kg}$ per min) } & \multicolumn{2}{|c|}{ Oxidation ( $\mu \mathrm{mol} / \mathrm{kg}$ per min) } & \multicolumn{2}{|c|}{ Concentration $(\mu \mathrm{mol} / \mathrm{l})$} \\
\hline & Mean & SE & Mean & SE & Mean & SE \\
\hline \multicolumn{7}{|c|}{ Human subjects in post-absorptive state } \\
\hline Acetate & $8 \cdot 3$ & $\begin{array}{c}0.6 \\
\text { (6.5\% of ene }\end{array}$ & $\begin{array}{c}5 \cdot 7 \\
\text { expenditure) }\end{array}$ & 0.5 & 138 & 1 \\
\hline \multicolumn{7}{|c|}{ Dogs in $24 \mathrm{~h}$ fasted state } \\
\hline Acetate & $24 \cdot 4$ & $2 \cdot 4$ & & & 144 & 17 \\
\hline \multicolumn{7}{|c|}{ Rats in $22 \mathrm{~h}$ fasted state } \\
\hline Acetate & $29 \cdot 2$ & $3 \cdot 8$ & & & 356 & 23 \\
\hline Propionate & $4 \cdot 2$ & $1 \cdot 2$ & & & $6 \cdot 1$ & $3 \cdot 5$ \\
\hline Butyrate & $0 \cdot 31$ & 0.03 & & & 0.07 & $0 \cdot 2$ \\
\hline
\end{tabular}

*Since all subjects were either in a fasted or post-absorptive state, the turnover was considered to be the endogenous turnover. 
intravenously, the bicarbonate pool being primed with $\mathrm{NaH}^{13} \mathrm{CO}_{3}$. Arterial blood and expired air samples were then collected at regular intervals during the study. Endogenous turnover, oxidation rate and concentration of acetate were calculated from isotopic measurements (Table 1). About $70 \%$ of the endogenous acetate turnover was readily oxidised in these volunteers, who were in the post-absorptive state. Further details have been reported, in particular that $7 \%$ of the energy expenditure was attributable to acetate (Pouteau et al. 1996).

Furthermore, the endogenous acetate turnover was investigated in Beagle dogs. A whole-body turnover of acetate, equivalent to the endogenous turnover, of about $24 \mu \mathrm{mol} / \mathrm{kg}$ per min was observed in the $24 \mathrm{~h}$ fasted state (Pouteau et al. 1998a).

There have been fewer reports on endogenous production of propionate and butyrate in human subjects than there have been for acetate metabolism. The occurrence of endogenous propionate and butyrate metabolism in non-ruminants has been demonstrated by Breves et al. (1993), Sbaï et al. (1994) and Kien et al. (2000). Before undertaking a clinical trial for the evaluation of endogenous propionate and butyrate whole-body turnover in human subjects, a rat model was developed in which $\left[1-{ }^{13} \mathrm{C}\right]$ acetate, $\left[1-{ }^{13} \mathrm{C}\right]$ propionate or $\left[1-{ }^{13} \mathrm{C}\right]$ butyrate was infused intravenously at a rate of $1 \mu \mathrm{mol} / \mathrm{kg}$ per min, and arterial and portal blood was collected. Isotopic enrichment and concentration were measured and the endogenous turnover rates for acetate, propionate and butyrate were calculated. The ${ }^{13} \mathrm{C}$-isotopic enrichments of acetate, propionate and butyrate increased throughout the study period and reached a plateau during the last $0.5 \mathrm{~h}$ of the infusion. The isotopic enrichments of acetate, propionate and butyrate in the plasma of rats were 3.5 (SE 0.6), 21.9 (SE 3.7) and 76.6 (SE 1.7) MPE respectively. The concentrations and the peripheral endogenous turnover rates are shown in Table 1.

In summary, under these conditions, in animals and in human subjects in a fasted-state or in the post-absorptive state, the whole-body peripheral turnover of SCFA is essentially the endogenous production and utilisation.

There have been many determinations of SCFA turnover in non-ruminants and large discrepancies have been reported, probably due to analytical problems and physiological variations between individuals (Rocchiccioli et al. 1989; Kien et al. 1990; Bleiberg et al. 1992; Sbaï et al. 1994; Simoneau et al. 1994; Mittendorfer et al. 1998). Previous studies have shown that peripheral plasma acetate concentration increases in proportion to lactulose oral intake in healthy human subjects (Pomare et al. 1985). However, the concentration variable should be considered as only one factor in production and utilisation rates. The use of tracer techniques allows the dynamic situation to be determined by assessing the rates of production and utilisation (the turnover). Determination of the turnover adds another dimension to the accuracy of monitoring SCFA metabolism. Furthermore, the non-invasive aspect of using stable isotopes allows direct determination of SCFA turnover in the peripheral whole body in human subjects and in animals.

In the present work we determined the basal endogenous turnover of acetate in rats, dogs and human subjects using the same stable-isotope-tracer technique and analytical methods (Pouteau et al. 1996, 1998a). The endogenous acetate turnover increased with decreasing size of the species studied. This observation, not surprisingly, was consistent with the blood flow of the various species. As our determination of acetate turnover was of the first in human subjects, we compared present values with those of authors who had used radio-labelled tracers. The use of radioactivetracer techniques (Skutches et al. 1979) gave identical results for turnover of acetate in human subjects to our stable-isotope approach, $6-8 \mu \mathrm{mol} / \mathrm{kg}$ per min under similar physiological conditions. The similarity of the findings validated our acetate turnover determination using the stable-isotope infusion technique.

There are few data available on propionate and butyrate turnover in non-ruminants (Breves et al. 1993; Kien et al. 2000). The level of peripheral propionate production in rats was not insignificant (about $4 \mu \mathrm{mol} / \mathrm{kg}$ per $\mathrm{min}$ ), and probably originates from amino acid metabolism in the liver or the whole-body muscle mass. A slow, but not insignificant, turnover of butyrate was also found in the peripheral circulation of rats in the fasted state. Furthermore, the presence of endogenous butyrate in piglets (in the postprandial state) has been reported by Kien et al. (2000).

As a result of reported studies and the present work the endogenous turnover of acetate has been accurately assessed in animals and in healthy human subjects. Furthermore, the existence of a peripheral turnover of propionate and butyrate has been confirmed in rats. Determination of propionate and butyrate endogenous production rates in healthy human subjects would be an interesting question to address in future investigations.

\section{Clinical studies on exogenous and colonic production of acetate}

The exogenous production of SCFA, in particular that of acetate, was defined earlier as the measurable amount per time unit that is additional to the endogenous turnover, originating from the intestine and from splanchnic retention. Following determination of the whole-body turnover of SCFA (endogenous and exogenous rates), the splanchnic retention was taken into account in the calculation of the true in vivo production in the large intestine (the colonic production). The focus was on acetate, since acetate is the main SCFA reaching the peripheral circulation. A protocol was established in healthy volunteers to assess the splanchnic first-pass retention of acetate (Pouteau et al. 1996). The first part of the study consisted of an intragastric infusion of $\left[1-{ }^{13} \mathrm{C}\right]$ acetate for $3 \mathrm{~h}$ through a naso-gastric feeding tube without any priming injection, followed by an intravenous infusion of the same tracer for $3 \mathrm{~h}$ at an identical rate. It was shown that isotopic enrichment of the plasma acetate during the intragastric infusion of $\left[1-{ }^{13} \mathrm{C}\right]$ acetate was about twofold lower than that during the intravenous infusion. The apparent acetate turnover determined from the intragastric infusion was two to three times higher than when using the intravenous infusion $(21 \cdot 3$ (SE 3.2) and $8.0($ SE 1.0$) \mu \mathrm{mol} / \mathrm{kg}$ per min respectively; $P<0 \cdot 01$, paired $t$ test). The splanchnic first-pass retention of acetate was calculated to be about 60 (SE 7) \% in human subjects. 
Knowing the endogenous turnover and the splanchnic first-pass retention of acetate, it was possible to finalise a model to determine the colonic production of acetate in human subjects in vivo following ingestion of a nondigestible carbohydrate (Fig. 1). A clinical study was done that aimed to quantify the amount of acetate produced in the large intestine of volunteers who had received an oral dose of $20 \mathrm{~g}$ lactulose. The endogenous turnover was assessed before lactulose intake and then the change in whole-body acetate turnover throughout the kinetic study was determined. From this change the exogenous contribution was calculated and thereafter the colonic production (Pouteau et al. 1998b). A $7 \mathrm{~h}$ primed constant infusion of $\left[1-{ }^{13} \mathrm{C}\right]$ acetate was administered intravenously to healthy male adults before and after ingestion of $20 \mathrm{~g}$ lactulose. Before lactulose intake the plasma acetate concentration and $\mathrm{H}_{2}$ level were found to be low, and the endogenous turnover of acetate was similar to previous values $(6 \cdot 0$ (SE $0 \cdot 7) \mu \mathrm{mol} / \mathrm{kg}$ per min). After lactulose intake the mean breath $\mathrm{H}_{2}$ and the plasma acetate concentration increased and then returned to approximately initial values within $6 \mathrm{~h}$. Compared with the basal endogenous rate, wholebody acetate turnover increased, reached a plateau $(9 \cdot 2$ (SE $0.9) \mu \mathrm{mol} / \mathrm{kg}$ per min) and then decreased in a manner similar to that of the $\mathrm{H}_{2}$ and acetate levels (Fig. 2). The calculated exogenous acetate production increased (3.2 (SE 0.4) $\mu \mathrm{mol} / \mathrm{kg}$ per min) and then decreased similarly, the residual exogenous acetate production being about $0.5 \mu \mathrm{mol} / \mathrm{kg}$ per min (Fig. 2). The amount of exogenous acetate recovered in the peripheral blood was $56 \cdot 1$ (SE $4 \cdot 3$ ) mmol over $6 \mathrm{~h}$. Using our model it was determined that $20 \mathrm{~g}$ lactulose yields $140 \cdot 4$ (SE 11.7) mmol colonic acetate from bacterial fermentation (Pouteau et al. 1998b).

In summary, while determining instantaneous wholebody peripheral turnover of acetate in human subjects it was possible to evaluate, by comparison with the initial postabsorptive state, the appearance of exogenous production of acetate after an oral intake of non-digestible lactulose. Furthermore, when the splanchnic first-pass retention is accounted for the true intra-lumen production of acetate in

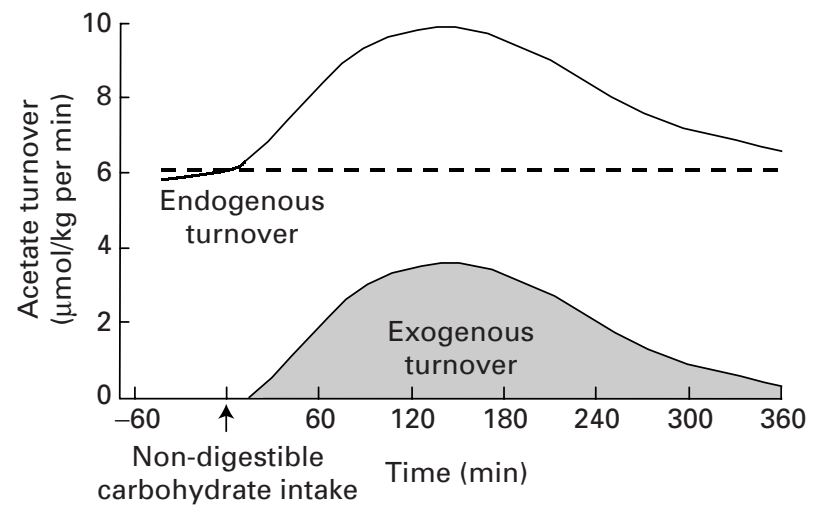

Fig. 2. Production of colonic acetate after oral intake of lactulose by healthy volunteers. Plot of the instantaneous whole-body turnover of acetate $(\mu \mathrm{mol} / \mathrm{kg}$ per min; - ) throughout the kinetic study. From -60 min to time zero $(\uparrow)$ the whole-body turnover represented the mean endogenous turnover (----). After ingestion of $20 \mathrm{~g}$ lactulose at time zero, the mean exogenous turnover of acetate (increased. (From Pouteau et al. 1998b.) the large intestine during bacterial fermentation could be calculated.

Numerous authors have attempted to evaluate the colonic fermentation process for complex carbohydrate in human subjects (Cummings, 1994) using stable isotopes (Kien et al. 1990, 1992, 1996), but there have been no reports on the determination of exogenous and colonic acetate production rates in healthy adults. One study reported a high acetate whole-body turnover $(64 \mu \mathrm{mol} / \mathrm{kg}$ per min) in preterm infants during lactose feeding and intra-gastric $\left[1-{ }^{13} \mathrm{C}\right]$ acetate infusion (Kien et al. 1992). Although preterm infants cannot be compared with adult subjects, the Kien et al. (1992) study probably overestimated acetate turnover because of splanchnic retention of the tracer. Interestingly, the same authors evaluated lactose fermentation in preterm infants using an oro-gastric infusion of $\left[1-{ }^{13} \mathrm{C}\right]$ glucose and $\mathrm{D}-\left[1-{ }^{13} \mathrm{C}\right]$ lactose (Kien et al. 1992, 1996), but the change in labelled glucose enrichment was assessed without direct measurement of acetate, propionate and butyrate production.

In the present work the colonic acetate originating from the bacterial fermentation process was determined in vivo. When compared with Miller \& Wolin's (1979) stoichiometric equation for carbohydrate fermentation, $86 \%$ of the acetate was recovered within the $6 \mathrm{~h}$ measurement period after lactulose ingestion. Some of the colonic acetate production might have been lost in faeces or utilised by bacteria. Nevertheless, the apparent loss could also be explained by residual exogenous acetate production at the end of the study, suggesting that the lactulose was not completely fermented, as suggested by the finding that the levels of $\mathrm{H}_{2}$ and acetate did not return exactly to initial levels. Cummings et al. (1989) estimated total SCFA production to be $9.4 \mathrm{mmol} / \mathrm{d}$ per $\mathrm{g}$ available fermentable substrate from the gastrointestinal tract of patients undergoing surgery. In the present work, if it is considered that acetate represents $60-75 \%$ of the total SCFA from carbohydrate fermentation (Bergman, 1990), about 185-205 mmol total colonic SCFA was thus produced from $20 \mathrm{~g}$ lactulose $(9 \cdot 25-10.25 \mathrm{mmol} / \mathrm{d}$ per $\mathrm{g}$ fermentable substrate). Our present model shows a very similar level of colonic SCFA production from non-digestible carbohydrate in healthy volunteers when compared with the findings of Cummings et al. (1989) and Cummings (1994) in patients undergoing surgery (i.e. conditions not applicable to normal healthy human subjects).

\section{Conclusion}

SCFA (acetate, propionate and butyrate) are produced mainly in the hindgut of non-ruminants, as well as in the whole-body peripheral circulation. The overall whole-body production of SCFA originates from an exogenous intestinal supply as well as from endogenous metabolism. In order to show the presence of the exogenous and endogenous components of SCFA production, a series of kinetic studies were carried out in animals and in human volunteers. To determine the endogenous SCFA turnover subjects were in the basal fasted or post-absorptive state. Exogenous production in human subjects following ingestion of lactulose was then investigated and the colonic production 
of acetate calculated. Similarly, whole-body peripheral production rates of propionate and butyrate could be determined in human subjects.

The originality of our work was the strategy and kinetics used to evaluate SCFA production from colonic bacterial fermentation in human subjects in vivo, requiring state-of-the-art analyses of peripheral plasma SCFA. Distinguishing the endogenous turnover from the wholebody peripheral turnover was the key to determining the exogenous turnover in vivo in human subjects, in order to evaluate production of SCFA in the large intestine. This unique approach could be further extended to the investigation of other non-digestible carbohydrates in healthy adults as well as in patients with diseases related to bacterial fermentation in the large intestine.

\section{Acknowledgements}

The authors would like to thank Isabelle Meirim and Pascale Maugère for their excellent technical assistance in analysing plasma SCFA; Hugues Piloquet and Kouroche Vahedi for their excellent performance in the clinical experiments; Laurent Fay, Diana Bedford and Christine Hughes for their critical reading of the manuscript, Bernard Messing, Dominique Darmaun and Florence Rochat for their relevant and constructive comments throughout the studies.

\section{References}

Annison EF \& White RR (1962) Further studies on the entry rates of acetate and glucose in sheep with special reference to endogenous production of acetate. Biochemical Journal 84, 546-552.

Barry JL, Hoebler C, Macfarlane GT, Macfarlane S, Mathers JC, Reed KA, Mortensen PB, Nordgaard I, Rowland IR \& Rumney CJ (1995) Estimation of the fermentability of dietary fibre in vitro: a European interlaboratory study. British Journal of Nutrition 74, 303-322.

Bergman EN (1990) Energy contributions of volatile fatty acids from the gastrointestinal tract in various species. Physiological Reviews 70, 567-590.

Bleiberg B, Beers TR, Persson M \& Miles JM (1992) Systemic and regional acetate kinetics in dogs. American Journal of Physiology 262, E197-E202.

Breves G, Schulze E, Sallmann HP \& Gadeken D (1993) The application of ${ }^{13} \mathrm{C}$-labelled short chain fatty acids to measure acetate and propionate production rates in the large intestines. Studies in a pig model. Zeitschrift für Gastroenterologie 31, 179-182.

Cummings JH (1994) Quantitating short chain fatty acids production in humans. In Short Chain Fatty Acids, pp. 11-19 [HJ Binder, JH Cummings and $\mathrm{KH}$ Soergel, editors]. London: Kluwer Academic Publishers.

Cummings JH, Gibson GR \& Macfarlane GT (1989) Quantitative estimates of fermentation in the hind gut of man. Acta Veterinaria Scandinavica 86, 76-82.

Cummings JH, Pomare EW, Branch WJ, Naylor CP \& Macfarlane GT (1986) Short chain fatty acids in the human large intestine, portal, hepatic and venous blood. Gut 28, 1221-1227.

Dankert J, Zijlstra JB \& Wolthers BG (1981) Volatile fatty acids in human peripheral and portal blood: quantitative determination by vacuum distillation and gas chromatography. Clinica Chimica Acta 110, 301-307.
Jensen MD, Heiling V \& Miles JM (1990) Measurement of non-steady-state free fatty acid turnover. American Journal of Physiology 258, E103-E108.

Kien CL, Ault K \& McClead RE (1992) In vivo estimation of lactose hydrolysis in premature infants using a dual stable tracer technique. American Journal of Physiology 263, E1002-E1009.

Kien CL, Chang DH, Murray RD, Ailabouni A \& Kepner J (1990) Measurement of stable isotopic enrichment of underivatized acetate by gas chromatography/mass spectrometry: Application to in vivo estimation of acetate production. Biological and Environmental Mass Spectrometry 19, 554-558.

Kien CL, Chang JC \& Cooper JR (2000) Butyric acid is synthesized by piglets. Journal of Nutrition 130, 234-237.

Kien CL, McClead RE \& Cordero L (1996) In vivo lactose digestion in preterm infants. American Journal of Clinical Nutrition 64, 700-705.

Knowles SE, Jarret IG, Filsell OH \& Ballard FJ (1974) Production and utilisation of acetate in mammals. Biochemical Journal 142, 401-411.

Macfarlane GT \& Cummings JH (1991) The colonic flora, fermentation, and large bowel digestive function. In The Large Intestine: Physiology, Pathophysiology and Disease, pp. 51-92 [SF Phillips, JH Pemberton and RG Shorter, editors]. New York: Raven Press.

McIntyre A, Gibson PR \& Young GP (1993) Butyrate production from dietary fibre and protection against large bowel cancer in a rat model. Gut 34, 386-391.

Miles JM, Ellman MG, McLean KL \& Jensen MD (1987) Validation of a new method for determination of free fatty acid turnover. American Journal of Physiology 252, E431-E438.

Miller TL \& Wolin MJ (1979) Fermentation by saccharolytic intestinal bacteria. American Journal of Clinical Nutrition 32, $164-172$

Mittendorfer B, Sidossis LS, Walser E, Chinkes DL \& Wolfe RR (1998) Regional acetate kinetics and oxidation in human volunteers. American Journal of Physiology 274, E978-E983.

Pomare EW, Branch WEJ \& Cummings JH (1985) Carbohydrate fermentation in the human colon and its relation to acetate concentrations in venous blood. Journal of Clinical Investigation 75, 1448-1454.

Pouteau E, Dumon H, Nguyen P, Darmaun D, Champ M \& Krempf M (1998a) Whole-body, peripheral and intestinal endogenous acetate turnover in dogs using stable isotopes. Journal of Nutrition 128, 111-115.

Pouteau E, Meirim I, Metairon S \& Fay LB (2001) Acetate, propionate and butyrate in plasma: determination of the concentration and isotopic enrichment by gas chromatography/mass spectrometry with positive chemical ionization. Journal of Mass Spectrometry 36, 798-805.

Pouteau E, Piloquet H, Maugeais P, Champ M, Dumon H, Nguyen P \& Krempf M (1996) Kinetic aspects of acetate metabolism in healthy humans using $\left[1-{ }^{13} \mathrm{C}\right]$ acetate. American Journal of Physiology 271, E58-E64.

Pouteau E, Vahedi K, Messing B, Flourie B, Nguyen P, Darmaun D \& Krempf M (1998b) Production rate of acetate during colonic fermentation of lactulose: a stable-isotope study in humans. American Journal of Clinical Nutrition 68, 1276-1283.

Powers L, Osborn MK, Yang D, Kien CL, Murray RD, Beylot M \& Brunengraber H (1995) Assay of concentration and stable isotope enrichment of short chain fatty acids by gas chromatography/mass spectrometry. Journal of Mass Spectrometry 30, 747.

Rémésy C, Demigné C \& Morand C (1995) Metabolism of shortchain fatty acids in the liver. In Physiological and Clinical Aspects of Short-chain Fatty Acids, pp. 171-190 [JH Cummings, JL Rombeau and T Sakata, editors]. Cambridge: University Press. 
Rocchiccioli F, Lepetit N \& Bougnère PF (1989) Capillary gas-liquid chromatography/mass spectrometry measurement of plasma acetate content and $2-{ }^{13} \mathrm{C}$ acetate enrichment. Biological Environmental Mass Spectrometry 18, 816-819.

Rumessen JJ, Franck YS \& Gudmand-Hoyer E (1992) Acetate in venous blood for determination of carbohydrate malabsorption. European Journal of Clinical Nutrition 46, S135-S136.

Sbaï D, Narcy C, Thompson GN, Mariotti A, Poggi F, Saudubray JM \& Bresson JL (1994) Contribution of odd-chain fatty acid oxidation to propionate production in disorders of propionate metabolism. American Journal of Clinical Nutrition 59, 1332-1337.

Seufert CD, Mewes W \& Soeling HD (1984) Effect of long-term starvation on acetate and ketone body metabolism in obese patients. European Journal of Clinical Investigation 14, 163-170.
Simoneau C, Pouteau E, Maugeais P, Marks L, Ranganathan S, Champ M \& Krempf M (1994) Measurement of whole body acetate turnover in healthy subjects with stable isotopes. Biological Mass Spectrometry 23, 430-433.

Skutches CL, Holroyde CP, Myers RN, Paul P \& Reichard GA (1979) Plasma acetate turnover and oxidation. Journal of Clinical Investigation 64, 708-713.

Veldman FJ, Nair CH, Voster HH, Vermaak WJH, Jerling JC, Oosthuizen W \& Venter CS (1999) Possible mechanisms through which dietary pectin influences fibrin network architecture in hypercholesterolaemic subjects. Thrombosis Research 93, 253-264.

Wolfe RR (1992) Radioactive and Stable Isotope Tracers in Biomedicine - Principles and Practice of Kinetic Analysis. New York: Wiley-Liss. 